OOPEN ACCESS

International Journal of Applied Research in Social Sciences

P-ISSN: 2706-9176, E-ISSN: 2706-9184

Volume 2, Issue 6, P.No. 152-166, December, 2020

Fair East Publishers

Journal Homepage: www.fepbl.com/index.php/ijarss

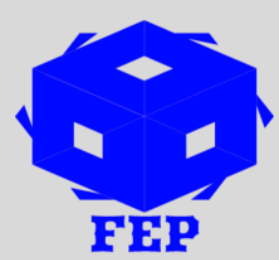

FEP

\title{
EXCLUSIVE BREASTFEEDING PRACTICES AMONG NURSES WORKING IN THE UPPER WEST REGIONAL HOSPITAL OF GHANA
}

\author{
Justice Agyei Ampofo ${ }^{1,2}$ Agartha Maame Yaw Antwi ${ }^{2}$, Antwi Abrefi Abigail ${ }^{3}$ \\ ${ }^{1}$ University for Development Studies, Tamale (Ghana) \\ ${ }^{2}$ University of Education, Winneba (Ghana) \\ ${ }^{3}$ University of Professional Studies, Accra (Ghana)
}

*Corresponding Author: Justice Agyei Ampofo

Corresponding Author Email: papajusty@gmail.com

Article Received: 10-11-20

Accepted: 13-12-20

Published: $30-12-2020$

Licensing Details: Author retains the right of this article. The article is distributed under the terms of the Creative Commons Attribution-Non Commercial 4.0 License (http://www.creativecommons.org/licences/by-nc/4.0/) which permits non-commercial use, reproduction and distribution of the work without further permission provided the original work is attributed as specified on the Journal open access page.

\begin{abstract}
Health workers are in general the first advocate of health benefits and are regarded as role models in whatever they teach especially when it comes to exclusive breastfeeding (EBF) practices. This study sought to find out the current breastfeeding practices of nurses (mothers) in the Upper West Regional Hospital. The study used a descriptive survey design involving 80 female health workers of the Wa Regional Hospital with a child aged more than 6 months. A structured questionnaire was administered to respondents. The study found out that majority of the respondents practiced exclusive breastfeeding. This means that majority of the female nurses working at the Wa Regional Hospital practiced exclusive breastfeeding. The study also found out that majority of the respondents' current feeding practice is breast milk with formula and they also used more than one (1) week in doing exclusive breastfeeding. The study found out that the level of maternal education, social class, mother's comfort in breastfeeding, father's occupation, religion, and hospital-related (obstetric and pediatric) factors inform mother's decision to initiate and continue exclusive breastfeeding. It emerged from the study that the attitudes of mothers regarding breastfeeding, mother-infant bonding, mode of delivery, and family support are also important in initiation and sustaining breastfeeding. Based on the findings of the study, it is recommended that Ministry of Health and Ghana Health Service workers especially female nurses working in the Wa Regional Hospital should
\end{abstract}


educate females who are mothers in the Wa Municipality of the Upper West Region of Ghana on the importance of exclusive breastfeeding practices. The study further recommends that the Ministry of Health and Ghana Health Service should empower health care providers (females) with skill and knowledge on exclusive breastfeeding practices and to initiate campaign on the importance of exclusive breastfeeding through social and developments women groups.

Keywords: Breastfeeding Practices, Nurses, Upper West, Regional Hospital, Ghana

\section{INTRODUCTION}

Breastfeeding is acknowledged as the optimal way to feed infants for the first six months by national and many other health organizations (United Nations Children's Fund, 2006; WHO, 2003). Despite its countless benefits to children and mothers, the continuation rates of effective breast feeding are low in Africa (Centers for Disease Control and Prevention, 2013). It is essential to understand how multiple factors affect breastfeeding practices in order to improve the duration of exclusive breastfeeding (Thulier \& Mercer, 2009). It is estimated that improved breastfeeding practices could save almost $\$ 13$ billion per year in the Africa where Ghana is not exception, if exclusive breastfeeding rates increased from $64 \%$ to $75 \%$ in the hospital and from $29 \%$ to $50 \%$ by six months of age (Bartick \& Reinhold, 2010).

A wide range of health benefits of exclusive breastfeeding to the infants and mothers have been well documented in various evidence-based research studies (Centers for Disease Control and Prevention, 2014). Numerous studies have shown that effective breast feeding between six months and two years of age has been associated with a decreased incidence of allergic disease, bacterial meningitis, bacteremia, diarrhea, respiratory tract infection, necrotizing enterocolitis, urinary tract infection, late onset sepsis in preterm babies, lymphoma, leukemia, hodgkin's disease, hypercholesterolemia, asthma, and post neonatal infants mortality (Wiener \& Wiener, 2011).

Research shows that prolonged and effective breast feeding has been associated with a reduction in the risk of sudden infants death syndrome, allergic dermatitis and respiratory infections in infants. Studies have concluded that effective breast feeding also provides many maternal benefits such as reducing the chances of developing adverse health outcomes such as obesity and ovarian and breast cancer in mothers (Thulier \& Mercer, 2009). In order to effectively increase breastfeeding rates, there is a need for multi-dimensional interventions that concurrently tackle different aspects of breastfeeding barriers (Dewey, 2001; Kramer, 2012). Successful breastfeeding is crucial to the curbing of infants malnutrition and achieving the millennium development goals four reducing child mortality and five improving maternal health. Based on available evidence, achievements of both goals are still far from the desired progress (Wiener \& Wiener, 2011).

In Ghana, while breastfeeding initiation is on the increase, the duration, and practice of exclusive breastfeeding among women who had their delivery in a health facility, and outside such facility, has remained low (Centers for Disease Control and Prevention, 2013). The early introduction of complementary feeding based on erroneous assumptions affects breastfeeding initiation and sustainability (Thulier \& Mercer, 2009; Cai et al, 2012). Among many people, a common belief around infant feeding is that exclusive breastfeeding is beneficial to both infants and mothers, but complementary feeding is essential for babies to adapt to other meals 
with ease. Besides normative expectations, personal experiences and networks of support have influence on the forms and quality of breastfeeding practices. Largely, these factors exert pressure on breastfeeding mothers thereby making their experience pleasurable or painful within time and space.

As an embodied experience, breastfeeding practices and experiences are context bound. Despite the available body of knowledge on breastfeeding practices in Ghana, there is inadequacy of studies investigating exclusive breastfeeding practices among nurses working in Ghana Health Service. This is why this study is conducted to find out the current feeding practices of mothers who attend the obstetric and gynaecological clinics during the first six weeks.

\section{REVIEW OF RELATED LITERATURE \\ Breast Feeding Practices of Mothers in Ghana}

The World Health Organization (2010) has recommended exclusive breastfeeding for the first six months after delivery as the best infants feeding practice. This is due to the numerous benefits effective breast feeding imparts on the health of both mothers and infants. It has been established that exclusively breastfed infants have lower incidence of respiratory tract and diarrhoeal infections. Also such infants have a decreased risk of acute otitis media, asthma, allergies, nutrient deficiencies, cancers and obesity (Ladomenou et al., 2010; Tenfelde, 2011). The presence of immunologic factors such as immunoglobulin A in breast milk protects the infant from contracting infections. Stuebe, Grewen and Meltzer-Brody (2013) have reported that infants who are exclusively breastfed are less likely to be hospitalized compared to their non-exclusively breastfed counterparts. They further suggested that the incidence of hospital visits during the first year of life decreases as the duration of breastfeeding increases. Exclusively breastfed infants have also been shown to exhibit higher cognitive functions to infants (WHO, 2002). This is due to the presence of docosahexaenoic acid in breast milk which contributes to the growth and the development of healthy eyes and nervous system (Drover et al., 2011; Ahluwalia, 2012; Al-Binali, 2012).

In addition to the benefits enjoyed by the infants, exclusively breastfeeding mothers experience delayed return of ovulation as well as lower rates of ovarian and premenopausal breast cancers (American Academy of Paediatrics, 2005). A strong bond is fostered between mothers and infants during the breastfeeding process (Alemayehu, 2009; Whelan, 2011; Nkala, 2011). Again, exclusive breastfeeding for the first 6 months has been associated with a faster postpartum weight loss in the mothers (Dewey et al., 2011; Tamiru, 2012).

In resource limited countries that also have a high burden of HIV transmissions and infections, exclusive breast feeding for the initial 6 months has been found to decrease the likelihood of mother-to-child transmission (MTCT) of HIV compared to mixed feeding (Yokoyama et al., 2006). The financial gains made by the family from exclusive breast feeding compared to mixed feeding or formula feeding is another advantage worthmentioning (Ladomenou et al., 2010). This is because money that would have been spent to purchase infant formula in addition to the time involved in preparing it for the baby would both be saved (Ukegbu et al, 20111 Brand, 2011).

Also, since exclusive breast feeding infants have lower incidence of morbidity, money that would have been spent on hospital admissions and medications would be saved (Bartick and Reinhold, 2010). Breastfeeding is considered as one of the major public health strategies for 
improving infants and child morbidity and mortality, improving maternal morbidity because of the wide range of benefits of exclusive breastfeeding to the mothers and infants (Abraka, 2009).

Ghana's exclusive breastfeeding rate has risen steadily from $7 \%$ in 1993 to $31 \%$ in 1998 and then to 53\% in 2003 (Godfrey \& Lawrence, 2010). The findings of the 2008 Ghana Demographic and Health Survey (GDHS) suggest that the percentage of Ghanaian children ever breast-fed is between $97-98 \%$. Within the same period, the percentage of infants who initiated breastfeeding within one hour after delivery was 52\%, a 6\% increase over the 2003 value of $46 \%$. Additionally, $82 \%$ of infants aged less than two months were reported to have been breast-fed exclusively (UNICEF, 2008). Conversely, only 49\% of infants were still being breast-fed exclusively by 4 to 5months. Furthermore, a total of $63 \%$ of infants below 6 months were breast-fed exclusively in 2008. Though this was an improvement upon the 2003 rate of $53 \%$, it was still below the $90 \%$ coverage target recommended by the World Health Organization (WHO). The results of the recent Ghana Demographic and Health Survey (2018) suggests that the rate of exclusive breast feeding has declined from $63 \%$ to $46 \%$.

\section{RESEARCH METHOLOGY}

\section{Research Methods}

A mixed method approach was adopted for this study, involving both qualitative and quantitative data collection methods. Quantitative data was collected using questionnaires. These tools captured the required data on feeding practices of mothers who attend the obstetric and gynecological clinics during the first six week. Qualitative data was captured using Key Informants Interview (KII) guides with key stakeholders at the hospital level. Specific key stakeholders were asked questions that are relevant to this study.

Mixed method approaches were used for this study because it can answer a broader and more complete range of research questions because the researchers are not confined to a single method or approach (Ampofo, 2020). Mixed-methods can also provide stronger evidence for a study's conclusions through convergence and corroboration of findings (Ampofo, 2020). The researcher used a concurrent mixed methods design in the current study. In a concurrent approach, two or more data collection instruments are administered within the same time frame. The researchers collected both forms of data (questionnaire and interview) at the same time during the study, and then integrated these data into the interpretation of the overall results (Creswell, 2013, Ampofo, 2020)

The purpose of using a mixed method design was to use both the responses obtained from the questionnaire and those from the interviews to provide a comprehensive analysis of the research questions asked. A secondary reason was the possibility of using the results from one instrument to confirm or corroborate findings from the other (Ampofo, 2020).

\section{Research Design}

The research is a descriptive survey through which views and opinions were sampled from nurses working at the Wa Regional Hospital in the Upper West Region of Ghana. Ampofo (2020) views descriptive survey as a design that portrays accurately the characteristic of particular individual situations or groups. In other words, the descriptive survey is a research method that is non-experimental and deals with the relating among non-manipulated variable. A descriptive survey also provides a quantitative or numeric description of trends, attitudes, or opinions of a population by studying a sample of that population. It includes cross-sectional 
and longitudinal studies using questionnaire or structured interviews for data collection, with the intent of generalizing from a sample to a population (Ampofo, 2020).

The descriptive survey was considered the most appropriate design for conducting this research because information gathered from the descriptive research can be meaningful or useful in diagnosing a situation since it involves describing, recording, analyzing and interpreting conditions that exist. The descriptive survey was again considered the most appropriate design for conducting this study because it is the one that deals with things as they currently are (Ampofo, 2020).

\section{The Study Area}

The study was conducted in Wa Regional Hospital in the Wa Municipality of the Upper West Region of Ghana. The researcher work experience has helped him gain access to the information needed for the successful completion of this study. The hospital is within my locality hence reducing the cost as well as risk involved in travelling. This makes the data collection process easy and convenient.

\section{Population}

The target population consisted of all the nurses at the Wa Regional hospital who have given birth or have done breast feeding before. The nurses are the targeted group because they are the health profession and exclusive breastfeeding is more relevant to them and also many of them are mothers as such they are capable of giving information necessary for the study.

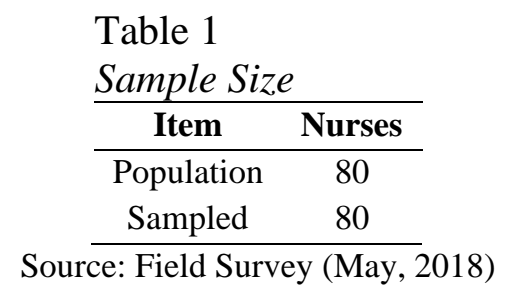

\section{Sample Size and Sampling Techniques}

All the nurses who have been mothers before at the Wa Regional Hospital were purposively selected for this study. Here all nurses were considered because they are they all have knowledge on exclusive breast feeding. A census survey was conducted. A census survey was conducted among the 80 nurses who have given birth before. According to Ampofo, Amoah and Peprah (2020), "a census is feasible when the population is small and variable, any sample we may draw may not be representative of the population from which it is drawn." Considered the target population in question (Nurses at the Wa Regional Hospital who have given birth before and did exclusive breast feeding), it is most appropriate to use the census survey.

\section{Instrumentation}

Questionnaire was used to collect data from respondents in this study. The questionnaire was both close ended and open ended questions using the Likert scale with options like (Very common, Common, Uncommon, Very uncommon, strongly agree, Agree, Disagree, Strongly Disagree and Ranking). It was divided into four sections which are as follows: Section A Personal data and Section B on the current feeding practices of mothers.

\section{Pretesting of the Instrument}

A pilot study was conducted in Wa Ahmadiya Hospital which has the same sociodemographic as that of the selected Wa Regional Hospital for this study. The questionnaires 
were administered to ten (10) nurses. The pilot study was done to improve the reliability of instrument. Changes were made to questions deemed inappropriate after the pilot study.

\section{Validity of the Instruments}

A research instrument is said to be valid when it measures what it is supposed to measure. Face validity is in relation to the misunderstanding and misinterpretation of the question. This was checked by way employing pretesting method. Content validity on the other hand refers to the capacity of the instrument to prove adequate coverage of a topic. Adequate preparation of the instrument under guidance of expert opinion and pre-testing of the question helped established the content validity.

\section{Reliability of the Study}

Reliability has to do with an instrument consistently producing the same result every time it is used. The test retest method was used to test for the reliability of the instrument. The questionnaires were administered to nurses of Wa Alhmadiya Hospital which has the same socio- demographic as that of Wa Regional Hospital. The same questionnaires were administered to them after two weeks. A correlation coefficient of 0.8 alpha levels was obtained which is considered reliable.

\section{Data Collection Procedure}

Data collection was done by the researcher. Permission was sort from the Upper West Regional Health Directorate through a written letter to use the respondents of the study. Personal presentation of the questionnaires to respondents was done so that the researcher could clarify any questions as well as explain the purpose of the study. Informed consent was sought from the respondent.

\section{Data Analysis}

Analysis of data provided facts and figures that enabled interpretation of the results and reaching conclusions from the findings of the study. All items of the questionnaires were coded. Items in the form of Likert scale were rated between $4-1$, with 4 being the highest and 1 being the lowest. Questionnaires were edited to ensure that clear, legible, relevant, and appropriate responses had been provided. The coded items and their corresponding frequencies were fed into the computer using the SPSS software programme. Data were analyzed using simple percentages and frequencies.

\section{Ethical Consideration}

Ethics are codes or rules that govern a practice or a profession. In research, the codes of conduct that govern it, to ensure the safety of participants is referred to as ethical considerations. In order to abide by these codes of conduct, participation in this research was only on a voluntary basis. No person was coerced or forced into participation. Anonymity and confidentiality of participants was ensured. Therefore the participants were not required to mention their names or anything else that could link them to the study. Participants of this study were also free from risks. Participation was only based on responses. So no harm came to the people who took part in this study Informed consent was sought before respondents were asked to fill the questions.

\section{PRESENTATION OF RESULTS}

\section{Demographic data of Respondents}

Section A of the questionnaires gathered data on the sex distribution of respondent's which is presented in the table below. 
Table 2

Sex Distribution of Respondents

\begin{tabular}{lcc}
\hline Sex & Frequency & Percentage (\%) \\
\hline Male & 0 & $0.00 \%$ \\
Female & 80 & $100.0 \%$ \\
\hline Total & $\mathbf{8 0}$ & $\mathbf{1 0 0 \%}$ \\
\hline \multicolumn{2}{c}{ Source: Field Survey (May, 2018) }
\end{tabular}

Table 2 presents the gender of participants who responded to the questionnaire items. From the table, 80 respondents were given questionnaire. All responded to the questionnaire. All the respondents 80 representing $100 \%$ were females. This is because the study focused on females thus nurses who have been given birth before or have done breast feeding) before. One aspect of the questionnaire gathered data from respondents on their age and this is what Table 3 presents.

Table 3

\begin{tabular}{lcc}
\multicolumn{3}{l}{ Age Distribution of Respondents } \\
\hline Age & Frequency & Percentage (\%) \\
\hline Below 25 & 5 & $6.25 \%$ \\
$25-30$ & 40 & $50.0 \%$ \\
$31-35$ & 30 & $37.5 \%$ \\
$36-40$ & 5 & $6.25 \%$ \\
Above 40 & - & - \\
\hline Total & $\mathbf{8 0}$ & $\mathbf{1 0 0 \%}$
\end{tabular}

The age distribution of the sample population is presented in Table 3. The table shows that majority of the respondents were between 25-30 years representing 40(50\%) of the respondents. This was followed by those between 31-35 years who also recorded 30(37.5\%), followed by those below 25 years and above 40 years respectively recording $5(6.25 \%)$ each. The implication of this is that, majority of respondents were older from 25 years which is above the age of maturity as such could give the relevant information needed for this study. One aspect of the questionnaire gathered data from respondents on their level of academic education and this is presented in Figure 1.

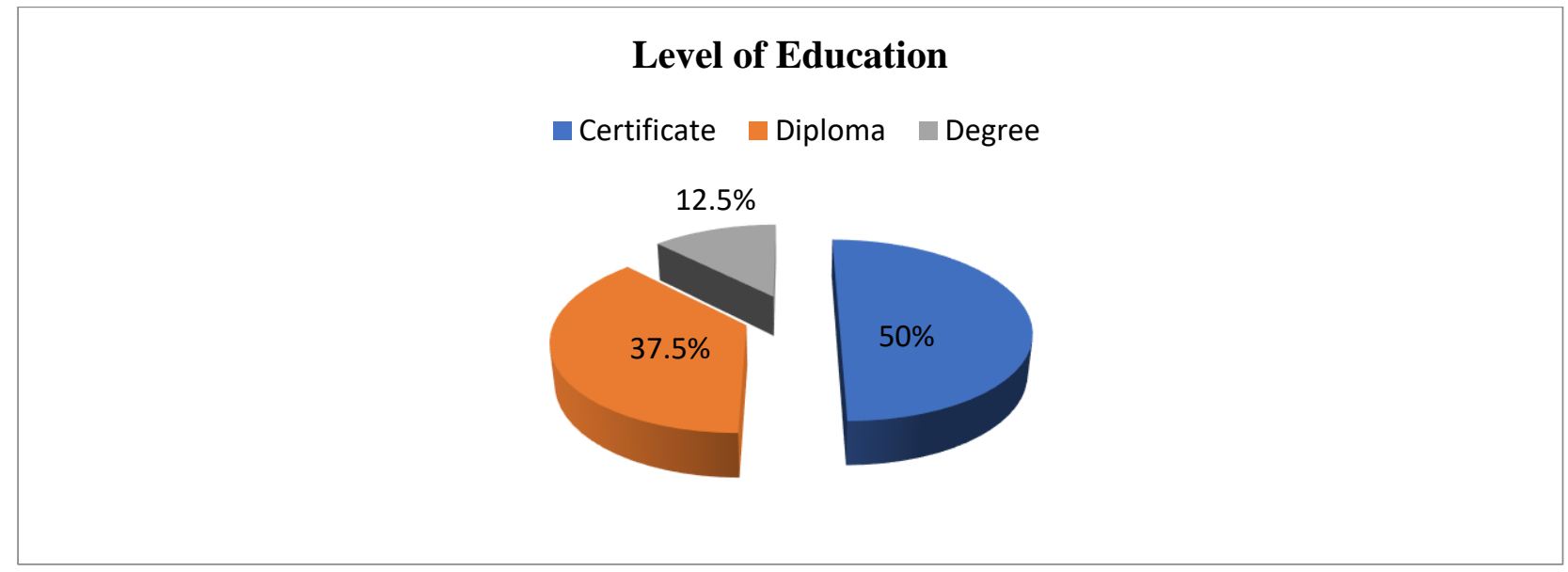

Figure 1: Highest Level of Education of Respondents Source: Field Survey (May, 2018) 
Figure 1 shows that $40(50 \%)$ of the respondents had a certificate in Nursing while $30(37.5 \%)$ of the respondents had diploma and the remaining 10 (12.5\%), have a degree. A deduction from the above is that majority of the respondents working as Nurses in the Wa Regional Hospital selected for the study are certificate and diploma holders.

One aspect of the questionnaire also gathered data from respondents on their working experience in the Nursing profession and this is presented in Figure 2.

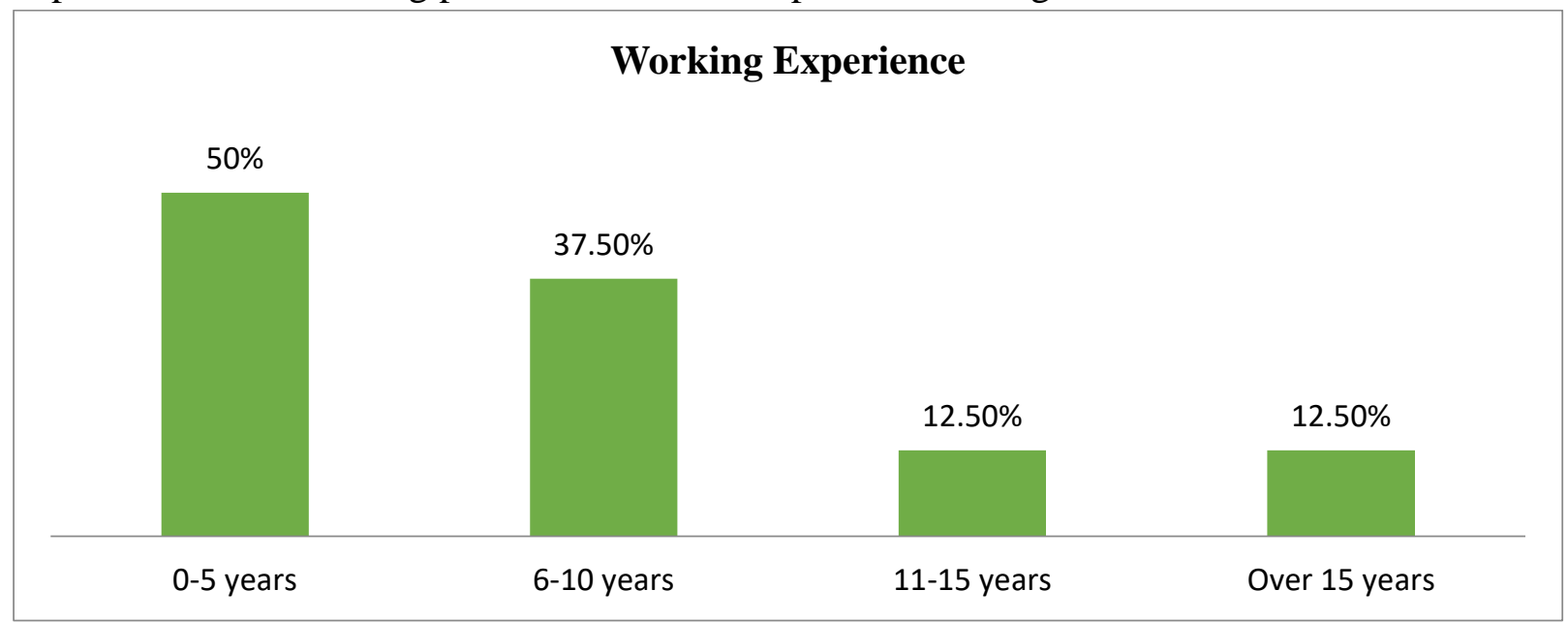

Figure 2: Working experience of Respondents

Source: Field Survey (May, 2018)

Figure 2 shows that majority of the respondents working as nurses in the Wa Regional Hospital $40(50 \%)$ have worked from $0-5$ years, whiles $30(37.5 \%)$ of the respondents have worked for 6-10 years, followed by $10(12.5 \%)$ respectively each who have worked from 11 15 years and over 15 years. The implication of this is that majority of nurses working at the Wa Regional Hospital who took part in this study have more working experience as such could be able to give the relevant information needed for this study.

\section{Analysis of Items}

The analyses of the items are based on the three research questions which are as follows:

1. What are the current feeding practices of mothers who attend the obstetric and gynecologic clinic during the first four weeks postpartum?

Research Question 1: What are the current feeding practices of mothers who attend the obstetric and gynecologic clinic during the first four weeks postpartum?

One aspect of the questionnaire gathered data from respondents on the age of their babies and this is presented in Figure 3. 


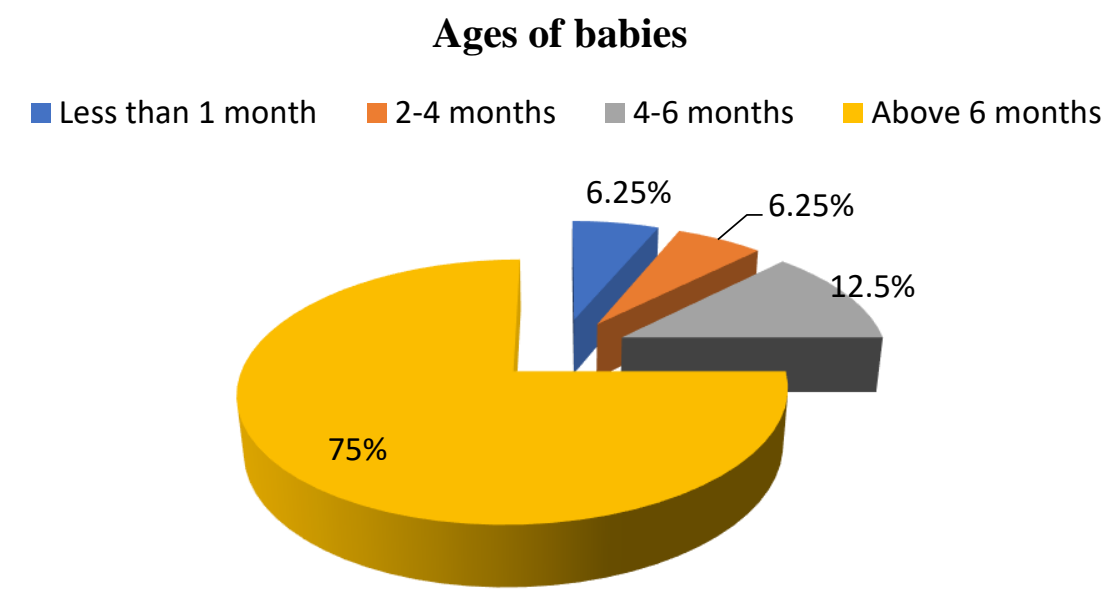

Figure 3: Ages of Respondents Babies

Source: Field Survey (May, 2018)

Results from Figure 3 shows that majority of the respondents 60 out of 80 representing $75 \%$ indicated that their babies are above 6 months, followed 10 out of the 80 respondents representing $12.5 \%$ indicated that their babies are between 4- 6 months whiles 5 out of the 80 respondents representing $6.25 \%$ respectively each indicated that their babies are less than one (1) month and 4-6 months.

One aspect of the questionnaire also gathered data from respondents whether they have practiced exclusive breast feeding before or are practicing exclusive breast feeding and this is presented in Figure 4.

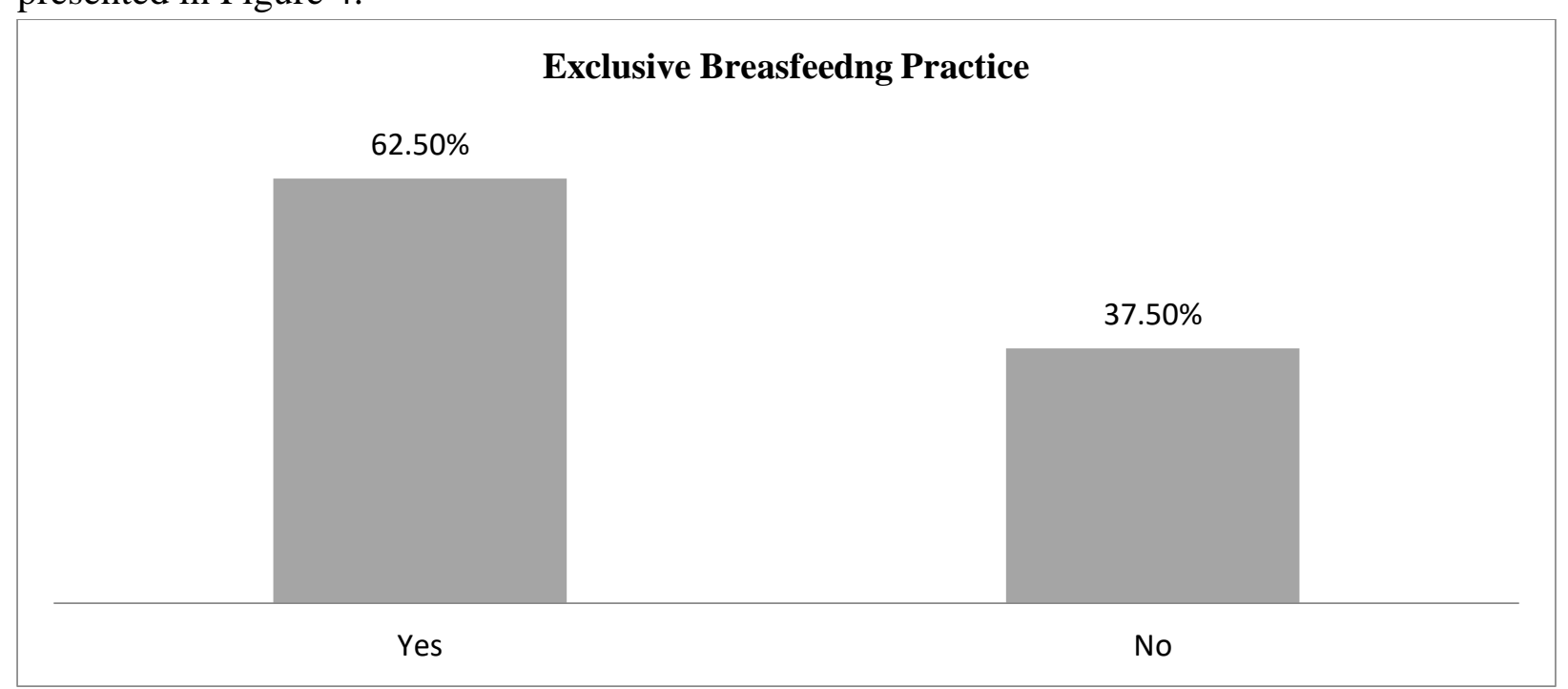

Figure 4: Exclusive Breastfeeding Practices among Respondents Source: Field Survey (May, 2018)

Results from Figure 4 shows that majority of the respondents 50 out of 80 representing $62.5 \%$ indicated that they practiced exclusive breastfeeding or are practicing exclusive breastfeeding whiles 30 out of 80 respondents representing $37.5 \%$ indicated that they are not practicing exclusive breastfeeding. The implication of this result means that majority of the female nurses working at the Wa Regional Hospital are practicing exclusive breastfeeding.

The results of this study disagree with the findings of Centers for Disease Control and Prevention (2014) which indicated that, about 50 percent of women do not practices exclusive 
breast feeding. Regardless its importance exclusive breast feeding is not commonly practiced among women in most of the sub Saharan countries (Ahluwalia, 2012).

One aspect of the questionnaire also gathered data from respondents on their current feeding practice and this is presented in Figure 5.

\section{Feeding Practices}

Exclusive breastfeeding (Only breast milk) $\quad$ Breast milk and formula $\square$ Formula feeding only

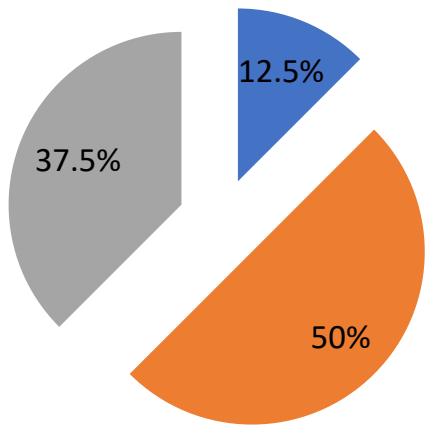

Figure 5: Current Feeding Practice of Respondents

Source: Field Survey (May, 2018)

Results from Figure 5 shows that majority of the respondents 40 out of 80 representing 50\% indicated that their current feeding practice is breast milk and formula, followed by 30 out of 80 representing $37.5 \%$ who indicated that their feeding practice is formula feeding only whiles 10 out of 80 representing $12.5 \%$ indicated that their current feeding practice is exclusive breastfeeding (only breast milk). These findings are consistent with the findings of other studies that it is not only maternal intention and attitude, but many other maternal demographic and individual variables associated with predicted breastfeeding duration (Ladomenou, 2010; Nkala, 2011; Tamiru, 2012).

One aspect of the questionnaire also gathered data from respondents on the duration of their exclusive breastfeeding practices and this is presented in Figure 6.

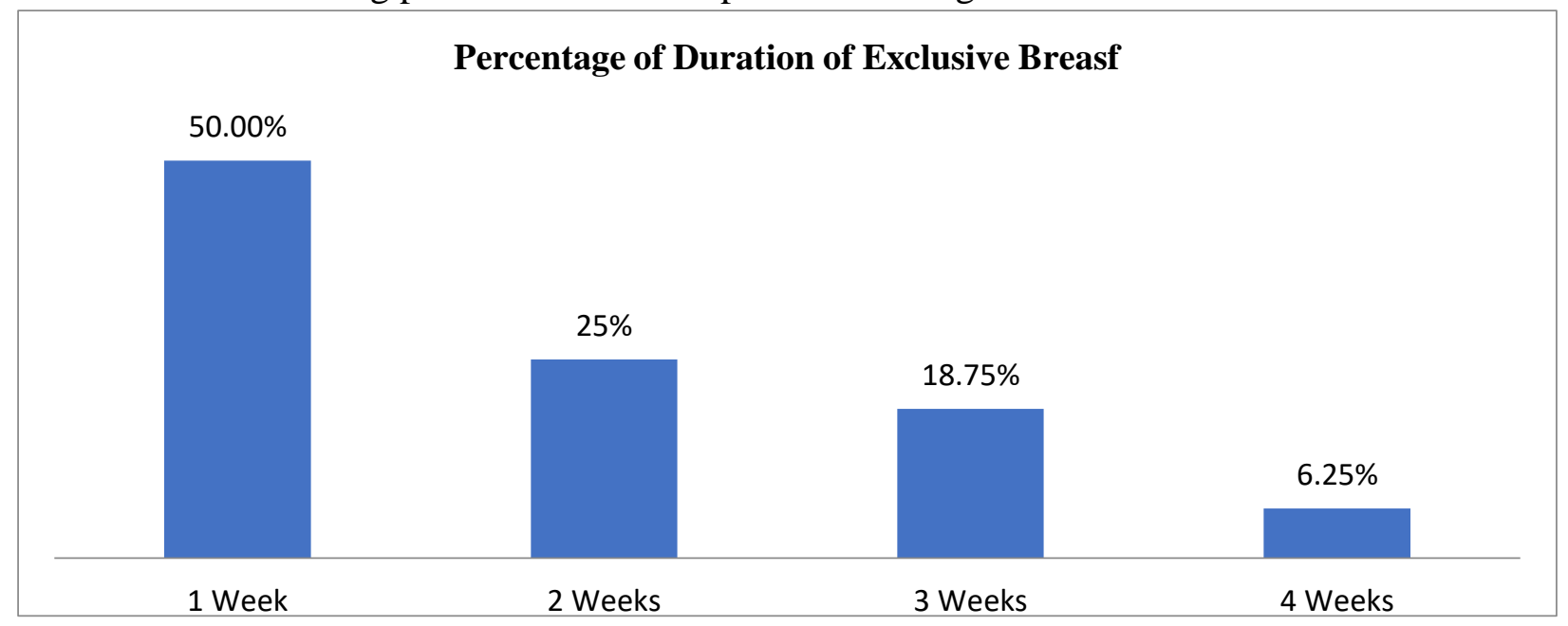

Figure 6: Respondents Exclusive Breastfeeding Duration Practices

Source: Field Survey (May, 2018)

Results from Figure 6 shows that majority of the respondents 40 out of 80 representing $50 \%$ indicated that they used 1 week in doing exclusive breast feeding. This was followed by 20 out of the 80 respondents representing $25 \%$ who indicated that they used 2 weeks for 
exclusive breastfeeding, followed by 15 out of the 80 respondents representing $18.75 \%$ who indicated that they used 3 weeks whiles 5 out of the 80 respondents representing $6.25 \%$ indicated that they used 4 weeks for their exclusive breastfeeding.

The findings of this study is in agreement with a study by Wiener (2011) who posited that there are many evidence-based documented breastfeeding promotional activities, EBF rates are still far below the stated Healthy People 2020 goals. Research indicates that for women who plan to breastfeed, experiences and support during the first hours and days after birth influence their later ability to continue breastfeeding (Centers for Disease Control and Prevention, 2013:2014).

To improve exclusive breastfeeding success and duration rates, hospital policies and practices to support breastfeeding are critical. Research suggests that mothers who room in with their babies during the entire hospital stay, breastfeed longer and are more likely to breastfeed exclusively compared with mothers who have limited contact with their babies or whose babies are in the nursery (Abraka, 2009; Al-Binali, 2012).

\section{DISCUSSION AND SUMMARY OF MAJOR FINDINGS}

The objective of the study was to find out the current feeding practices of mothers who attend the obstetric and gynaecological clinics during the first six weeks. It emerged from the study that majority of the respondents babies are more than six months. The study also found out that majority of the respondents practiced exclusive breastfeeding. This means that majority of the female nurses working at the Wa Regional Hospital practiced exclusive breastfeeding. The results of this study disagrees with the findings of Centers for Disease Control and Prevention (2014) which indicated that, about 50 percent of women who are nurses do not practices exclusive breastfeeding.

The study found out that majority of the respondents current feeding practice is breast milk with formula and they also used more than 1 week in doing exclusive breast feeding. The findings of this study is in agreement with a study by Godfrey (2010) who posited that there are many evidence-based documented breastfeeding promotional activities, EBF rates are still far below the stated Healthy People 2020 goals. Research indicates that for women who plan to breastfeed, experiences and support during the first hours and days after birth influence their later ability to continue breastfeeding (Drover, 2011).

To improve exclusive breastfeeding success and duration rates, hospital policies and practices to support breastfeeding are critical. Research suggests that mothers who room in with their babies during the entire hospital stay, breastfeed longer and are more likely to breastfeed exclusively compared with mothers who have limited contact with their babies or whose babies are in the nursery (Godfrey, 2010; Drover, 2011).

\section{CONCLUSION}

Main results occurred from this study have established the main barriers for continuation of exclusive breastfeeding among mothers during the first six weeks postpartum. These are education level, food and nutrition, place of delivery and source of information and influence on breastfeeding.

\section{RECOMMENDATIONS}

Following from the findings and conclusions of this study, the researcher strongly recommends that the Ministry of Health and Ghana Health Service should empower skill and knowledge to health care providers who are providing $\mathrm{RCH}$ services direct dealing with 
nursing mothers, so that they will become mental to support supervision to nursing mothers and to initiate campaign on the importance of exclusive breastfeeding through social and developments women groups. Also Ghana Health Service (specifically Wa Regional Hospital) should collaborate with stockholders responsible for exclusive breastfeeding to empower and strengthen the social media to report regular information on good eating behavior in relation to EBF to increases mothers awareness.

Many of the findings expressed in this research have implications for practice and policy development. Healthcare professionals and childbirth educators need to identify and promote strategies to increase exclusive breastfeeding initiation and continuation rates. Research indicates that inadequate maternal health education is a leading reason that breastfeeding is not initiated or continued (Stuebe, 2013). Evidence based educational strategies and individual support will help women gain confidence in breastfeeding by minimizing their uncertainties and fears.

For nurses who are mothers working at the Wa Regional Hospital who are returning to work or school, employers need to be encouraged to establish policies that allow flexible schedules and appropriate places to breastfeed. Another key strategy for improving the rate of exclusive breastfeeding (EBF) among low-income mothers is to build partnerships among healthcare professionals, legislators, employers and the community by working together to support breastfeeding. Maternity hospitals should continue to reform maternity care practices that promote continuation of EBF for the recommended period of six months.

\section{Acknowledgements}

The research team wants to thank the editorial board of Fair East Publishers and also Antwi Abrefi Abigail (Law student at University of Professional Studies, Accra, Ghana) for her sound support and excellent contributions.

\section{Conflict of Interest Statement}

No conflict of interest has been declared by the author.

\section{Funding}

The researcher has not received any support for the publication of this paper.

\section{References}

Abraka, E. (2009). Common Factors Responsible as Barrier of Breastfeeding to the Baby Less Than Six Months Period, Delta State University Community university.

Agho, K. E., Dibley, M. J., Odiase, J. I., \& Ogbonmwan, S. M. (2011). Determinants of exclusive breastfeeding in Nigeria. BMC Pregnancy \& Childbirth, 11, 2.

Al-Binali, A. M. (2012). Breastfeeding knowledge, attitude, and practice among school teachers in Abha female educational district, southwestern Saudi Arabia. International Breastfeeding Journal, 7(1), 10-15. Doi:10.1186/1746-4358-7-10

Alemayehu, T., Haidar, J., \& Habte, D. (2009). Determinants of exclusive breastfeeding practices in Ethiopia. Ethiopian Journal of Health Development 23(1), 12-18. 
Ahluwalia, I. B., Li, R., \& Morrow, B. (2012). Breastfeeding practices: Does method of delivery matter? Maternal and Child Health Journal, 16 Suppl, 2231-2237. doi:10.1007/s10995-012-1093-9

American Academy of Pediatrics. (2005). Policy statement: Prevention of pediatric overweight and obesity. Pediatrics, 112(2), 424-430.

Ampofo, A. J. (2020). Challenges of Student Management Information System (MIS) in Ghana: A case study of University for Development Studies, Wa Campus. International Journal of Management \& Entrepreneurship Research, 2(5), 332-343.

Ampofo, A. J. (2020). Contributions of the hospitality industry (hotels) in the development of Wa. International Journal of Advanced Economics, 2(2), 21-38.

Ampofo, A. J. (2020). Implications of poor waste disposal management practices on senior high schools within the Wa Municipality of Ghana. International Journal of Applied Research in Social Sciences, 2(3), 53-70.

Ampofo, A. J. (2020). The nature of mortgage repayment plans in Ghana. Finance \& Accounting Research Journal, 2(3), 91-104.

Ampofo, A. J. (2020). Rural housing challenges in the Upper West Region of Ghana: A case study of Kulmasa. International Journal of Management \& Entrepreneurship Research, 2(4), 194-211.

Ampofo, A. J. (2020). Waste disposal management practices in selected senior high schools within the Wa Municipality of Ghana. International Journal of Management \& Entrepreneurship Research, 2(4), 273-290.

Ampofo, A. J., Amoah, S. T., \& Peprah, K. (2020). Examination of the current state of government buildings in senior high schools in Wa Municipal. International Journal of Management \& Entrepreneurship Research, 2(3), 161-193.

Bartick, M., \& Reinhold, A. (2010). The burden of suboptimal breastfeeding in the United States: A pediatric cost analysis. Pediatrics, 125, e1048-e1056.

Brand, E., Kothari, C., \& Stark, M. (2011). Factors related to breastfeeding discontinuation between hospital discharge and 2 weeks postpartum. Journal of Perinatal Education, 20(1), 36-44. doi:10.1891/1058-1243.20.1.36

Cai, X., Wardlaw, T., \& Brown, D. W. (2012). Global trends in exclusive breastfeeding. International Breastfeeding Journal 7(12), 1-5.

Centers for Disease Control and Prevention. (2013b). Breastfeeding resources. Retrieved from http://www.cdc.gov/breastfeeding/resources/guide.htm

Centers for Disease Control and Prevention. (2013c). Progress in increasing breastfeeding and reducing racial/ethnic differences in United States, 2000-2008. Retrieved from http://www.cdc.gov/mmwr/preview/mmwrhtml/mm6205a1.htm

Centers for Disease Control and Prevention. (2014). Breastfeeding report card 2014. Retrieved from http://www.cdc.gov/breastfeeding/pdf/2018breastfeedingreportcard.pdf

Creswell, J.W. (2013). Qualitative inquiry and research design: Choosing among five Approaches ( $3^{\text {rd }}$ ed.). Thousand Oaks: Sage.

Dewey, K, G., Cohen, R. J., Brown, K. H., and Rivera, L. L. (2001). Effects of exclusive breastfeeding for four versus six months on maternal nutritional status and infant 
motor development: results of two randomized trials in Honduras. The Journal of Nutrition 131, 262-267.

Drover, J. R., Hoffman, D. R., Castneda, Y. S., Morale, S. E., Garfield, S., Wheaton, D. H., \& Birch, E. E. (2011). Cognitive function in 18-month-old term infants of the DIAMOND study: A randomized, controlled clinical trial with multiple dietary levels of docosahexaenoic acid. Early Human Development 87(3), 223-230.

Ghana Statistical Service (GSS), Ghana Health Service (GHS), and ICF Macro. 2009. Ghana Demographic and Health Survey 2008/2018. Accra, Ghana: GSS, GHS, and ICF Macro.

Godfrey, J., \& Lawrence, R. (2010). Toward optimal health: the maternal benefits of breastfeeding...Ruth A. Lawrence, M.D. Journal of Women's Health, 19(9), 15971602. doi:10.1089/jwh.2010.2290

Kramer, M., \& Kakuma, R. (2012). Optimal duration of exclusive breastfeeding. Cochrane Database of Systematic Reviews, 8. Doi:10.1002/14651858.CD003517

Ladomenou, F., Moschandreas, J., Kafatos, A., Tselentis, Y., \& Galanakis, E. (2010). Protective effect of exclusive breastfeeding against infections during infancy: a prospective study. Archives of Disease in Childhood 95, 1004-1008.

Nkala, T. E., \& Msuya, S. E. (2011).Prevalence and predictors of exclusive breastfeeding among women in Kigoma region, Western Tanzania: a community based crosssectional study. International Breastfeeding Journal 6(17), 2-7.

Stuebe, A. M., Grewen, K., \& Meltzer-Brody, S. (2013). Association between maternal mood and oxytocin response to breastfeeding. Journal of Women's Health, 22(4), 352-361.

Tamiru, D., Belachew, T., Loha, E., \& Mohammed, S. (2012). Sub-optimal breastfeeding of infants during the first six months and associated factors in rural communities of JimmaArjo Woreda, Southwest Ethiopia. Biomed Central Public Health 12(363), 1-9.

Tenfelde, S., Finnegan, L., \& Hill, P. (2011). Predictors of breastfeeding exclusivity in a WIC sample. Journal of Obstetric, Gynecologic, and Neonatal Nursing, 40(2), 179-189.

Thulier, D., \& Mercer, J. (2009). Variables associated with breastfeeding duration. Journal of Obstetric, Gynecologic, and Neonatal Nursing: JOGNN/NAACOG, 38(3), 259-268. doi:10.1111/j.1552-6909.2009.01021.x

United Nations Children's Fund (2006). Breastfeeding. Retrieved from http://www.unicef.org/nutrition/index_24824.html

UNICEF (2008). Overview of breastfeeding patterns. Retrieved from http://www.childinfo.org/breastfeeding_ghana.html accessed on $7^{\text {th }}$ January, 2018.

Ukegbu, A. U., Ukegbu, P. O., Okpara, M., Onyeonoro, U. U., and Ubajaka, C. F. (2011).Determinants of breastfeeding patterns among mothers in Anambra State, Nigeria. South Africa Journal of Child Health 5(4), 112-116.

Whelan, B., McEvoy, S., Eldin, N., \& Kearney, J. (2011). What primary health professionals need to promote breastfeeding? Practice Nursing, 22(1), 35-39.

Wiener, R. C., \& Wiener, M. A. (2011). Breastfeeding prevalence and distribution in the USA and Appalachia by rural and urban setting. Rural \& Remote Health, 11(2), 1-9.

World Health Organization. (1998). Postpartum care of the mother and newborn: A practical guide. Geneva, Switzerland: Author. 
World Health Organization. (2002). The optimal duration of exclusive breastfeeding: A systematic review. Geneva, Switzerland: Author.

World Health Organization. (2010). The optimal duration of exclusive breastfeeding: A systematic review. Geneva, Switzerland: Author. 